\title{
Exploring the level of lockdown fatigue and effect of personal resilience and coping behaviours on university students during the covid-19 pandemic: a cross-sectional analysis from Iraq
}

\author{
Bassam Abdul Rasool Hassan ${ }^{1}$. Ali Haider Mohammed ${ }^{1,2}$. Abdulrasool M. Wayyes ${ }^{1}$. Sinan Subhi Farhan ${ }^{3}$. \\ Omar Abdulwahid Al-Ani ${ }^{1}$. Ali Blebil ${ }^{1,2}$. Juman Dujaili ${ }^{1,2}$
}

Accepted: 21 January 2022

(c) The Author(s) 2022

\begin{abstract}
Governments worldwide have imposed lockdowns in their countries to restrict unnecessary movement and curb the spread and transmission of the Covid-19 as a mitigation measure. The education sector has also implemented rapid changes, and this has transformed the operational procedures for both students and lecturers. As the pandemic has progressed, its emotional and psychological toll is equally bearing on students, leading to lockdown fatigue. This study aimed to investigate the level of lockdown-induced fatigue and its correlation with personal resilience and coping skills among university students in Iraq. This study used quantitative methods of research using a cross-sectional study design. A questionnaire survey was distributed electronically among 819 university students in Iraq. The study used three standardised scales: the lockdown fatigue scale, brief resilience scale, and coping behaviours questionnaire for data collection. Descriptive and inferential statistical analysis were done using SPSS. Overall, students indicated a high level of lockdown fatigue with a mean score of 33.48out of 50. Fear of personal safety and the wellbeing of the family was the most fear expressed by the students. The ability to go through stressful times and unpleasant events was the most common worry among the students. Female, urbanised, and science field students were the most students who suffered from lockdown-induced fatigue. However, positive coping behaviours and personal resilience were significantly correlated with decreasing fatigue levels during the lockdown period. Level of lockdown fatigue accelerated in an alarming stage among university students in Iraq. Hence, students need to build their emotional resilience and learn how to navigate surviving hard times and bounce back after a loss. This could be facilitated by counselling services being availed to educational and social institutions to benefit university students.
\end{abstract}

Keywords Lockdown-fatigue $\cdot$ Covid-19 $\cdot$ Personal resilience $\cdot$ Coping behaviours $\cdot$ Students

\section{Introduction}

The Covid-19 pandemic poses a global health emergency, and it has rendered significant economic and health problems. Many governments worldwide have imposed stringent

Ali Haider Mohammed

alihaider.mohammed@monash.edu;

alishanshoo193@gmail.com

1 Department of Pharmacy, Al Rafidain University College, Baghdad 10001, Iraq

2 School of Pharmacy, Monash University Malaysia, Jalan Lagoon Selatan, 47500 Bandar Sunway, Selangor, Malaysia

3 Department of Anesthesia, College of Medical Science Technology, University of Mashreq, Baghdad 10001, Iraq measures, which include mandatory lockdown, social distancing and home confinement orders to mitigate disease control and reduce the rate of transmission (Xiao \& Torok, 2020). For example, starting from 1 March 2020, the Iraqi government ushered in its strategy of partial and total lockdown measures to curb the spread of Covid-19. The lockdown measures have stringent clauses, including the restriction of interprovince travel and the closure of schools and universities (Jebril, 2020). While the lockdown measures were effective in curbing the rate of transmission and the spread of the virus, they were detrimental to the mental and psychological wellbeing of people, especially young people (Marroquín et al., 2020; Volkan \& Volkan, 2020). Among the varied effects of the lockdown or home confinement induced by the Covid-19 pandemic, fatigue was one of the most commonly reported effects; which was aptly described 
as a mental or physical state of exhaustion and lower energy levels (Labrague \& Ballad, 2020; Labrague, 2021).

Lockdown fatigue is described as the impact on an individual dealing with uncertainty, anxiety, emotions, feelings, and the lack of control over the future due to the Covid19 pandemic and imposed lockdowns (Labrague \& Ballad, 2020). While the lockdown fatigue may manifest in different forms, it stems from a common cause, which is the efforts that individuals are making to acclimatise and adapt to the evolving situation of the global pandemic. The Covid-19 pandemic has affected all facets of life from its onset. People have had to change their operational procedures to comply with the regulations set by the government to contain the virus, such as lockdown and closure of non-essential facilities. This has cast a shadow of uncertainty on how the future will be like for everyone if the pandemic ends (Goldstein et al., 2021).

The education sector is not exempt from the immense regulations which the government of Iraq imposed to contain the transmission and spread of the virus. Due to the nationwide lockdown, students have had to stay home and adopt online learning (Mahase, 2020). Another non-essential activity is also restricted, limiting the alternative activities that students can participate in to pass the time. Social gatherings are prohibited, and inter-city travel is strictly monitored, leaving the majority of the students in isolation with their families. The lack of social contact has resulted in immense feelings of isolation, leading to people who have never had psychological problems developing them due to the pandemic (Aboagye et al., 2021). Furthermore, the limited amount of any alternative activity has exposed students to the full extent of the virus as they keep up with the news bulletin, witness the loss of lives and economic difficulty (Maatuk et al., 2021).

The sense of impending doom has led to psychological stress and emotional difficulties, and it is against this background, students are experiencing lockdown fatigue. Due to constant news of the loss of life and witnessing the loss of family members, the pandemic has inevitably exposed students to trauma (Field et al., 2021). However, the trauma response of individuals often varies, with other individuals quickly recovering from stressful events while others have a longer time to recover. Such challenging times would require one to have the flexibility and emotional balance, but this is not the case for most of the population as the situation constantly evolves, presenting new challenges and dynamics to live with (Abbasi, 2020). Individuals also vary in their coping behaviours; some would resort to spirituality and holistic lifestyle practices, and others would succumb to negative coping behaviours such as alcoholism and drug abuse (Pigaiani et al., 2020). Therefore, the level of lockdown fatigue among university students are still unclear, and the approaches and strategies that students may do to overcome this matter are still unidentified clearly nationally and internationally. Hence, the current study will fill this gap of knowledge by determining the lockdown fatigue and provide additional insight into the role of coping behaviour and personal resilience in facing such a challenge among university students in Iraq.

\section{Methods}

\section{Study design, samples, and setting}

A cross-sectional study utilising an online data collection approach was conducted during the five months of the mandatory lockdown implemented in Iraq due to the coronavirus pandemic from December 2020 to April 2021. This study included students who enrolled in colleges and universities from different provinces in Iraq. Using the Qualtrics sample size calculator, an estimation of the required sample size was performed. A sample size of at least 385 was found to be required for three predictors to attain an $80 \%$ power, with an effect size of 0.05 and alpha set at 0.05 . One thousand students were initially invited from 15 universities located in different regions in Iraq to generalise the findings; however, 819 responded to our online survey (response rate $=81.9 \%$ ). To qualify for the study, students had to: a) be currently enrolled in a college or university, b) be a full-time student, and c) consent to participate in the study.

\section{Instrument tool}

Three different questionnaires using five standardised scales were used to gather data, including the lockdown fatigue scale (Labrague \& Ballad, 2020), Brief Resilience Scale (Smith et al., 2008), and coping behaviours questionnaire (Savitsky et al., 2020).

\section{Lockdown fatigue scale}

This scale was used to evaluate signs of exhaustion associated with the lockdown or home confinement measures to slow the spread of coronavirus. The 10 -item scale was answered by the participants on a 5-point Likert-type scale that ranged from 1 (never) to 5 (always). The highest possible score was 50, and the scores were categorised as indicating mild (score 1-15), moderate (score 16-30), high (score 31-45), and severe (score 46-50) fatigue. In addition, the reliability and validity of the scale were checked, where the scale's content validity was 0.91 and the test-retest reliability was 0.93 . 


\section{Brief resilience scale}

This six-item scale determined students' ability to bounce back from traumatic or unpleasant events associated with the pandemic and the imposed lockdown measure. Students answered the scale by responding to a 5-point Likert-type scale ranging from 0 (strongly agree) to 5 (strongly disagree). The reliability and validity of the scale were checked, where the scale's content validity was 0.89 and the test-retest reliability was 0.90 .

\section{Coping behaviours questionnaire}

This scale examined the ways college and university students coped during the mandatory lockdown period. The scale comprised eight items that were categorised into four dimensions: seeking information and consultation, use of humour, mental disengagement and spirituality/sources of support. Participants answered the items using a 5-point Likert-type scale that ranged from 1 (strongly disagree) to 5 (strongly agree). The reliability and validity of the scale were checked, where the scale's content validity was 0.94 and the test-retest reliability was 0.88 .

\section{Data collection}

The Institutional Research Ethics Committee of Al Rafidain University College granted the ethical approval for this study (EC-68-2021). Since the schools were closed and teaching was online during the data collection period, an online survey was created using SurveyMonkey and sent to the students' email addresses. Basic information about the study and the letter seeking their consent was contained on the introductory page of the online form. Names were not requested during submission to ensure the anonymity of the participants. The online survey was conducted for a period of five-month from December to April 2021, which corresponds to the six months of the mandatory lockdown measure in Iraq. Follow-up emails were sent to students on a weekly basis to remind them to complete the survey.

\section{Data analysis}

Data completeness was checked before entering into SPSS version 26 . To quantify the data, we calculated frequencies, standard deviations, and weighted means. The normality of the data distribution was confirmed via the KolmogorovSmirnov test. Bivariate analysis was facilitated using the independent t-test, and Pearson's correlation coefficient ( $r$ ) to examine correlations between key study variables. The level of statistical significance was set as $P<0.05$.

\section{Results}

\section{Socio-demographic characteristics}

Students from universities and tertiary institutions around Iraq were approached to participate in this survey. Just over half of the respondents were male (50.4\%), and nearly all respondents were of Arabic ethnicity (95.4\%). The majority of the students were living in urban areas (91.3\%), and the most dominant field of study was STEM (80.4\%). The mean age was $23.65 \pm 6.31$, and the means scores were just over 3 for lockdown fatigue, personal resilience and coping skills (Table 1).

\section{Participants' lockdown fatigue}

The participants were asked how they feel during the lockdown period induced by the Covid-19 pandemic. One of the most dominant feelings which the students experienced is the fear of their own family's safety and wellbeing (mean $=3.87$ ). The students also indicated that facing feelings of sadness and depression and fearing that "this pandemic will never end soon " $($ mean $=3.5 ; 3.4)$ are the other most indicators that exhausted them during the lockdown period. On the other hand, the students reported that the feelings which they had the least were loss of sleep over the pandemic and any headaches or body pains ( mean $=2.8$; 3.0). The students also felt having a certain level of difficulty

Table 1 Socio-demographic characteristics of respondents $(n=819)$

\begin{tabular}{lll}
\hline Characteristic & & Frequency (\%) \\
\hline Gender & Male & $413(50.4)$ \\
& Female & $406(49.6)$ \\
Ethnicity & Arab & $781(95.4)$ \\
& Kurdish & $38(4.6)$ \\
Type of university/college & Public & $146(17.8)$ \\
& Private & $673(82.2)$ \\
Type of residence & Urban & $748(91.3)$ \\
& Rural & $71(8.7)$ \\
Study field & STEM (e.g. Science, & $659(80.4)$ \\
& Technology, Engineer- \\
& ing and Mathematics) & \\
& Non- & $160(19.6)$ \\
& STEM(e.g.Humanities, & \\
& Arts, Literature and & \\
Age & Management) & SD \\
Leckdown fatigue score & 3.34 & 6.31 \\
Coping skills score & Mean & 0.67 \\
\hline
\end{tabular}


in concentrating or being distracted easily amid lockdown periods. Overall, based on the scale, the total lockdown means is 33.48 , indicating that students have a high level of lockdown fatigue (Table 2).

\section{Participants' personnel resilience}

The participants were asked how they bounce back from traumatic or unpleasant events associated with the pandemic and imposed lockdowns (Table 3). Participants indicated that their greatest difficulty was coping through the duration of stressful and challenging times imposed by the pandemic. The highest mean score was recorded on the item "I have a hard time making it through stressful events" (mean=3.44). This was followed by the ability to snap back after something terrible happens to the students. The participants, however, indicated that as the hard times subside, they are better at bouncing back into wellbeing. The least mean score was recorded on the item "I tend to bounce back quickly after hard times" $($ mean $=3.21)$.

\section{Participants' coping skills}

The participants were asked which of the activities they resorted to in coping with the mandatory lockdown period.
"I put my trust in God" was the most common action that participants did to cope during the lockdown (mean $=4.33$ ). This was followed by searching for information on any questions which they had pertaining to the lockdown. The participants also resorted to finding alternative activities to distract them from the events occurring and seeking emotional support from friends and relatives. The least common action was resorting to alcohol and drugs to feel better (Table 4).

\section{Correlation between lockdown fatigue and key study variables}

The difference and correlation between lockdown fatigue and key variables among the participants were analysed (Table 5). Among the variables tested, the mean differences among gender, ethnicity, type of residence and study field and lockdown fatigue are significantly different. We conclude that female, urbanised, and science field students had a higher fatigue level than their reference. In contrast, the Pearson $r$ correlation test showed that there is a significant $(P<0.05)$, positive moderate and strong correlation $(r=0.52 ; 0.74)$ between lockdown fatigue and personnel resilience and coping skills, respectively.

Table 2 Responses of participants on the Lockdown Fatigue Scale $(n=819)$

\begin{tabular}{|c|c|c|c|c|}
\hline Items & Minimum & Maximum & Mean & Std. Deviation \\
\hline I worry a lot about my personal and family's safety during this pandemic & 1.00 & 5.00 & 3.8657 & 1.15605 \\
\hline I have difficulty concentrating and distracted easily & 1.00 & 5.00 & 3.3162 & 1.08281 \\
\hline I frequently felt weak or tired as a result of this lockdown & 1.00 & 5.00 & 3.3736 & 1.08764 \\
\hline I have been feeling irritable & 1.00 & 5.00 & 3.3187 & 1.17108 \\
\hline I have difficulty falling or staying asleep over thinking about this pandemic & 1.00 & 5.00 & 2.8144 & 1.26539 \\
\hline I have felt sad and depressed as a result of this lockdown & 1.00 & 5.00 & 3.5079 & 1.17570 \\
\hline I have been losing my interests to do the usual things I love & 1.00 & 5.00 & 3.3578 & 1.22033 \\
\hline I have been experiencing a general sense of emptiness & 1.00 & 5.00 & 3.3919 & 1.09744 \\
\hline I have been experiencing headaches and body pains & 1.00 & 5.00 & 3.0855 & 1.21322 \\
\hline I have thoughts that this pandemic will never end soon & 1.00 & 5.00 & 3.4530 & 1.22771 \\
\hline Total lockdown fatigue score & 10 & 50 & 33.48 & 6.60 \\
\hline
\end{tabular}

Table 3 Responses of participants on the Brief Resilience Scale $(n=819)$

\begin{tabular}{|c|c|c|c|c|}
\hline Items & Minimum & Maximum & Mean & Std. Deviation \\
\hline I tend to bounce back quickly after hard times & 1.00 & 5.00 & 3.2198 & 1.11800 \\
\hline I have a hard time making it through stressful events & 1.00 & 5.00 & 3.4432 & 1.06518 \\
\hline It does not take me long to recover from a stressful event & 1.00 & 5.00 & 3.2991 & 1.10329 \\
\hline It is hard for me to snap back when something bad happens & 1.00 & 5.00 & 3.4212 & 1.10990 \\
\hline I usually come through difficult times with little trouble & 1.00 & 5.00 & 3.3907 & 1.04248 \\
\hline I tend to take a long time to get over setbacks in my life & 1.00 & 5.00 & 3.3944 & 1.19984 \\
\hline
\end{tabular}


Table 4 Participants' responses on the Coping Behaviours skills $(n=819)$

\begin{tabular}{|c|c|c|c|c|}
\hline Items & Minimum & Maximum & Mean & Std. Deviation \\
\hline I try to get advice from someone about what to do & 1.00 & 5.00 & 3.4853 & 1.12300 \\
\hline When I have a question about the situation, I search for information & 1.00 & 5.00 & 3.7914 & 1.08062 \\
\hline I use alcohol or drugs to make myself feel better & 1.00 & 5.00 & 2.3444 & 1.45595 \\
\hline I put my trust in God & 1.00 & 5.00 & 4.3346 & 1.07077 \\
\hline I turn to work or other substitute activities to take my mind off things & 1.00 & 5.00 & 3.5702 & 1.06334 \\
\hline I eat more than usual to calm myself down & 1.00 & 5.00 & 3.2996 & 1.20810 \\
\hline I enjoy the jokes about the situation & 1.00 & 5.00 & 3.4284 & 1.08694 \\
\hline I try to get emotional support from friends or relatives & 1.00 & 5.00 & 3.5361 & 1.17427 \\
\hline
\end{tabular}

Table 5 Difference and correlation between lockdown fatigue with other scales and demographic variables

\begin{tabular}{|c|c|c|c|c|}
\hline Characteristics & Categories & Mean (SD) & Test Statistics & $P$ value \\
\hline Gender ${ }^{\&}$ & $\begin{array}{l}\text { Male } \\
\text { Female }\end{array}$ & $\begin{array}{l}32.71(6.24) \\
34.27(6.87)\end{array}$ & -3.42 & $0.001 *$ \\
\hline Type of university ${ }^{\&}$ & $\begin{array}{l}\text { Public } \\
\text { Private }\end{array}$ & $\begin{array}{l}32.94(5.92) \\
33.60(6.73)\end{array}$ & -1.10 & 0.272 \\
\hline Type of residence ${ }^{\&}$ & $\begin{array}{l}\text { Urban } \\
\text { Rural }\end{array}$ & $\begin{array}{l}33.73(6.55) \\
30.96(6.67)\end{array}$ & 3.42 & $0.001^{*}$ \\
\hline Study field ${ }^{\&}$ & $\begin{array}{l}\text { STEM } \\
\text { Non-STEM }\end{array}$ & $\begin{array}{l}35.45(6.58) \\
33.63(6.68)\end{array}$ & -3.25 & $0.001 *$ \\
\hline Personnel resilience score mean ${ }^{\#}$ & - & - & 0.52 & $0.0001 *$ \\
\hline coping skills score mean ${ }^{\#}$ & - & - & 0.74 & $0.0001 *$ \\
\hline
\end{tabular}

\&t-test for independent group

\#Pearson $r$ correlation

*Significant value $(p>0.05)$

\section{Discussion}

Lockdown fatigue among individuals is a growing concern for the healthcare community as the pandemic persists with new variants of the coronavirus emerging. Despite evidence that young people are more likely to develop fatigue due to lockdown measures, there are no studies on how individual resilience and coping skills reduce fatigue in university students conducted in the Middle East, particularly in Iraq. Lockdown fatigue is a psychological phenomenon that has stemmed from the Covid-19 pandemic and increasingly affects students (Labrague, 2021). With the pandemic coming in waves and an upsurge of new infections, it would likely lead to lockdowns in the future for an uncertain period. One of the significant concerns, that Iraqi students have worried about during the lockdown period, is the fear of personal and family safety. Students were often concerned with whether they will survive the pandemic without contracting the virus (Amanzio et al., 2021). They would also be worried whenever they experience symptoms similar to those of the Covid-19 virus, such as headaches, sore or dry throat, fevers and low energy levels. This concern is heightened in students with family members who are at a higher risk of contracting the virus. These family members with diabetes, high blood pressure, cancer and other immunosuppressive conditions have expressed their distress and essential workers in the healthcare industry (Majumdar et al., 2020; Mohammed et al., 2020). Additional stress comes from having to cope with individuals who need to undergo treatment from the virus, given that they would need to be cautious due to counteractions of medication. Thus, chances of recovery would be compromised. Internationally, there is still an immense concern over individuals who have been working through the pandemic as essential workers (Vishwakarma et al., 2021). Their families would have anxiety over their safety from contracting the virus and recovery from illness. This is consistent with the study of Pachiyappan et al., which highlighted that students who have family members who are essential workers in the healthcare settings were found to be more concerned over the virus. This anxiety would heighten in periods where there are high death tolls and surges in new infections (Pachiyappan et al., 2021).

Students demonstrated feelings of sadness and depression due to the lockdown, and this is rationalised by the complex set of circumstances that they are facing. The education system has been disrupted, and there have been measures such as virtual learning, which have been introduced to ensure 
continuity in the education system. However, virtual learning is not as convenient as it is presumed to be (Sharma et al., 2020). While it may be considered simply stopping face-toface classes and switching to learning from home, it requires much more commitment and has its own challenges. Similar notions are observed from the findings of $\mathrm{Bu}$ et al., in the United Kingdom, and Reicher and Drury, which explored how studying from home during the pandemic would be for students under the stress of the pandemic (Bu et al., 2020; Reicher \& Drury, 2021). For freshmen, not all students live in stable homes which are conducive for studying. Family dynamics and living arrangements often curb the efficacy of virtual learning. In addition, learning from home while also facing economic difficulties, challenges and illnesses limit the engagement of students. This has resulted in students struggling to keep up with their performance at school and even losing interest in studying (Naddeo et al., 2021).

Moreover, our findings highlighted that female student had a high level of fatigue compared to the male student. This is probably because of gender differences in the expression of sentiments and emotions such as concern, fear, sadness, anxiety, and pain and bodily discomfort. Men, according to several pieces of evidence, tend to suppress their emotions and feelings, whereas women are more vocal in expressing their emotions (Chaplin et al., 2008; Tolin \& Foa, 2008). This finding confirms a long-held gender stereotype in Iraqi culture, according to which the expression of thoughts, feelings, and emotions is more acceptable for women than for men. Therefore, this study highlights the critical need to implement gender-tailored strategies to successfully treat the adverse impacts of the lockdown measure and reduce fatigue. Besides that, other groups of students who significantly reported a high level of fatigue are science students and those who are residents in urban areas. Empirical studies had proved that major scientific students are more stressed and exhausted than non-science students. This is because they have a high workload, more lessons and labs, respecting deadlines, balancing university and more private life (Portoghese et al., 2019). These pressures have been related to a higher risk of depression and lower academic performance, consequently worsening their level of fatigue during the lockdown period.

Another important finding was the positive moderate correlation between university students' personal resilience skills and lockdown fatigue. Personal resilience is essential as it enables one to navigate challenges and unpleasant circumstances to continue accomplishing their goals. Our students' sample demonstrated that they have a hard time making it through stressful events. Hence, the personal resilience of students has been challenged by the lockdown, as they have to continue with a common journey, which is their education. This is tested by how the students have continued studying and their rate of success (Labrague et al., 2020).
Overall, students have been able to continue with their improvised methods of study, improving students' ability to self-study and research. However, the mental toll and pressure of continuing with education despite personal hardships and failure have been a key feature of the pandemic (Savitsky et al., 2021). Individuals' time to recover from setbacks varies, which differentiates the students who are able to cope and those who are still unwell from the lockdown period (Cosmas, 2020). A previous scholar conducted by Migliorini et al. indicated how resilience had been tested in students, especially those on the brink of completing their studies who have an uncertain future to navigate (Migliorini et al., 2021). Therefore, the lockdown fatigue dampens the motivation of students to study or be proactive in their studies.

Individuals often develop both conscious and non-conscious coping mechanisms when they are going through unpleasant and stressful events. This was supported in our study, where coping skills was strongly correlated with the level of lockdown fatigue. This probably occurs due to the reality that some situations cannot be changed or be easily remedied; therefore, the individual is the one who has to adjust and cope with the stressful situations (Zhang et al., 2021). Ideally, coping mechanisms should be positive in helping the individual cope without inflicting personal harm in both the short and long term. Negative coping mechanisms such as binge-eating, alcohol and drug abuse are temporarily numb the individual from the current situation, but shortly after they inflict harm on the individual rather than helping them (Khan, 2021). From our present study, one of the most common coping mechanisms adopted by the students was placing their trust in God, which is, resorting to spirituality to search for answers for this dire situation. While the concept of divinity is varied among individuals, the commonly held belief is that resorting to divinity in stressful times would lead to relief, guidance and protection (Kadir, 2020). This is consistent with the study of Molteni et al., which indicates that in the period surrounding the lockdown, people of different faiths have been increasingly committed to their various religions as they seek relief from the pandemic (Molteni et al., 2021). Students who practised their religion regularly were more resilient than those who did not have any strong ties to any religion (Prazeres et al., 2021).

Apart from religious activities, students have also been occupying their minds with various activities during the stressful situations in lockdown. Notably, students have been using social media and participating in various activities which build a sense of community to curb the loneliness introduced by the lockdown (Nitschke et al., 2021). The discovery of new hobbies and indoor activities has been a key factor in coping with the mental fatigue induced by the lengthy lockdown. Studies by Devi indicate that due to the lockdown and restrictions, individuals often develop 
a timetable that enables them to spend their day without amplifying the abnormality such as waking up later, being slower in their routines and increased interest in home-care and wellbeing (Devi, 2020). These activities make it feasible for individuals to find emotional support from friends and relatives through socialising. However, this would be dependent on the emotional capacity of the friends and relatives, given that the pandemic and lockdown has affected all facets of society in drastic ways (Amanzio et al., 2021).

Lastly, another interesting coping approach that students were doing during the lockdown period is searching for information to gain insight into how they can effectively deal with the pandemic. Popular searches include 'number of Covid-19 cases' and 'home remedies' (Chandra, 2020). Students have also been lately keen on learning about the various vaccinations which are available and how they would work. With vast information available on the internet, students also enjoy sharing their knowledge with companions leading to lengthy conversations about the pandemic. This would give the individual seeking information a sense of control over the situation as they would not be susceptible to any factors which they are unaware of (Wasil et al., 2021).

\section{Strength and limitations of the study}

The survey was distributed across 15 universities located in the south, north, east, and west of Iraq so that findings can be generalised as it was representative of the university and college students in Iraq. The limitations of this study are the evolving scope of the Covid-19 pandemic and the possibility of future lockdowns occurring. The uncertainty of the period in which the pandemic will exist is also another limitation of the study. In addition, the responses gathered from this study are based on emotional responses; thus, they may be prone to bias; however, this is addressed by choosing a sufficient sample size for the study.

\section{Conclusion}

The imposition of compulsory lockdown and home confinement as a strategy to reduce the rate of Covid-19 transmission led university students to experience significant levels of fatigue in Iraq. This study provided tangible evidence which links higher personal resilience and coping skills among university students with lower levels of fatigue triggered by the lockdown. From the results of this study, it is necessary to instigate activities and methods which build personal resilience and foster positive coping strategies as methods of reducing high levels of lockdown fatigue and all detrimental mental and psychological issues related to the pandemic. Furthermore, government authorities and regulators should continuously evaluate the efficacy of the measures stipulated by the lockdown and strategies on how these measures can be eased without endangering students' health.

Authors' contributions All persons who meet authorship criteria are listed as authors, and all authors certify that they have participated sufficiently in the work to take public responsibility for the content.

Funding Open Access funding enabled and organized by CAUL and its Member Institutions.

Data availability Data and other materials are available upon request from the corresponding author.

\section{Declarations}

Ethical statement All procedures performed in this study were in accordance with the ethical standards of the institutional research committee and with the 1964 Helsinki Declaration and its later amendments or comparable ethical standards. The Institutional Research Ethics Committee of Al Rafidain University College granted the ethical approval for this study (EC-68-2021).

Consent to participate Informed consent was obtained from all individual participants in the study.

Consent to publish Participants signed informed consent regarding publishing their de-identified data.

Conflict of interest The authors state that they have no real, potential or apparent conflict of interest.

Open Access This article is licensed under a Creative Commons Attribution 4.0 International License, which permits use, sharing, adaptation, distribution and reproduction in any medium or format, as long as you give appropriate credit to the original author(s) and the source, provide a link to the Creative Commons licence, and indicate if changes were made. The images or other third party material in this article are included in the article's Creative Commons licence, unless indicated otherwise in a credit line to the material. If material is not included in the article's Creative Commons licence and your intended use is not permitted by statutory regulation or exceeds the permitted use, you will need to obtain permission directly from the copyright holder. To view a copy of this licence, visit http://creativecommons.org/licenses/by/4.0/.

\section{References}

Abbasi, K. (2020). Behavioural fatigue: A flawed idea central to a flawed pandemic response. British Medical Journal Publishing Group.

Aboagye, E., Yawson, J. A., \& Appiah, K. N. (2021). COVID-19 and E-learning: The challenges of students in tertiary institutions. Social Education Research., 1-8.

Amanzio, M., Canessa, N., Bartoli, M., Cipriani, G. E., Palermo, S., \& Cappa, S. F. (2021). Lockdown effects on healthy cognitive aging during the COVID-19 pandemic: A longitudinal study. Frontiers in Psychology, 12. 
Bu, F., Steptoe, A., \& Fancourt, D. (2020). Loneliness during a strict lockdown: Trajectories and predictors during the COVID-19 pandemic in 38,217 United Kingdom adults. Social Science \& Medicine., 265, 113521.

Chandra, Y. (2020). Online education during COVID-19: Perception of academic stress and emotional intelligence coping strategies among college students. Asian education and development studies., 10(2), 229-238.

Chaplin, T. M., Hong, K., Bergquist, K., \& Sinha, R. (2008). Gender differences in response to emotional stress: An assessment across subjective, behavioral, and physiological domains and relations to alcohol craving. Alcoholism: Clinical and Experimental Research., 32(7), 1242-1250.

Cosmas, G. (2020). Psychological support in uplifting university students' happiness in fighting the coronavirus lockdown. Postmodern Openings., 11(2), 31-42.

Devi, S. (2020). Psychological resilience and coping strategies during Covid-19 pandemic lockdown. J Xian Univ Archit Technol., 12, 2925-2933.

Field, T., Mines, S., Poling, S., Diego, M., Bendell, D., \& Veazey, C. (2021). COVID-19 lockdown fatigue. American Journal of Psychiatric Research and Reviews, 4(1), 27.

Goldstein P, Yeyati EL, Sartorio L. Lockdown fatigue: The diminishing effects of quarantines on the spread of COVID-19. 2021.

Jebril, N. (2020). Impact of the COVID-19 pandemic on the environment-a case study of Iraq. SSRN Electronic Journal, (Preprint), 10.

Kadir, A. A. (2020). Planned problem-solving strategy, resilience and element of religion in coping of covid 19 disease in Malaysia. International Journal of Psychosocial Rehabilitation, 24(01), $5476-5484$.

Khan, M. A. (2021). COVID-19 and the learning, teaching, assessment, and personal experiences of UK-based international students during lockdown. Handbook of Research on Lessons Learned From Transitioning to Virtual Classrooms During a Pandemic: IGI Global, page 23, 144-166.

Labrague, L. J. (2021). Pandemic fatigue and clinical Nurses' mental health, sleep quality and job contentment during the COVID-19 pandemic: The mediating role of resilience. Journal of Nursing Management, 29(7), 1992-2001.

Labrague, L., \& Ballad, C. A. (2020). Lockdown fatigue among college students during the covid-19 pandemic: Predictive role of personal resilience, coping behaviours, and health, 57(4), 1905-1912.

Labrague LJ, De los Santos JAA, Falguera C. (2020). Social and emotional loneliness among college students during the COVID-19 pandemic: The predictive role of coping behaviours, social support, and personal resilience., 57(4), 1578-1584

Maatuk, A. M., Elberkawi, E. K., Aljawarneh, S., Rashaideh, H., \& Alharbi, H. (2021). The COVID-19 pandemic and E-learning: Challenges and opportunities from the perspective of students and instructors. Journal of Computing in Higher Education., 1-18.

Mahase, E. (2020). Covid-19: Was the decision to delay the UK's lockdown over fears of "behavioural fatigue" based on evidence? British Medical Journal Publishing Group.

Majumdar, P., Biswas, A., \& Sahu, S. (2020). COVID-19 pandemic and lockdown: Cause of sleep disruption, depression, somatic pain, and increased screen exposure of office workers and students of India. Chronobiology international., 37(8), 1191-1200.

Marroquín, B., Vine, V., \& Morgan, R. (2020). Mental health during the COVID-19 pandemic: Effects of stay-at-home policies, social distancing behavior, and social resources. Psychiatry Research, 293, 113419

Migliorini, L., De Piccoli, N., Cardinali, P., Rollero, C., Marzana, D., Arcidiacono, C., et al. (2021). Contextual influences on Italian university students during the COVID-19 lockdown: Emotional responses, coping strategies and resilience. Community Psychology in Global Perspective., 7(1), 71-87.

Mohammed, A. H., Blebil, A., Dujaili, J., \& Rasool-Hassan, B. A. (2020). The risk and impact of COVID-19 pandemic on immunosuppressed patients: Cancer, HIV, and solid organ transplant recipients. AIDS reviews., 22(3), 151-157.

Molteni, F., Ladini, R., Biolcati, F., Chiesi, A. M., Dotti Sani, G. M., Guglielmi, S., et al. (2021). Searching for comfort in religion: Insecurity and religious behaviour during the COVID-19 pandemic in Italy. European Societies, 23(sup1), S704-SS20.

Naddeo, A., Califano, R., \& Fiorillo, I. (2021). Identifying factors that influenced wellbeing and learning effectiveness during the sudden transition into eLearning due to the COVID-19 lockdown. Work, 68(1), 45-67.

Nitschke, J. P., Forbes, P. A., Ali, N., Cutler, J., Apps, M. A., Lockwood, P. L., et al. (2021). Resilience during uncertainty? Greater social connectedness during COVID-19 lockdown is associated with reduced distress and fatigue. British Journal of Health Psychology., 26(2), 553-569.

Pachiyappan, T., Kumar, K. V., Mark, P., Venugopal, R., Jilumudi, D., \& Palanisamy, B. (2021). Effects of excessive usage of electronic gadgets during COVID-19 lockdown on health of college students: An online cross-sectional study. Asian Journal of Pharmaceutical Research and Health Care., 13(2), 139-145.

Pigaiani, Y., Zoccante, L., Zocca, A., Arzenton, A., Menegolli, M., Fadel, S., et al. (Eds.). (2020). Adolescent lifestyle behaviors, coping strategies and subjective wellbeing during the COVID-19 pandemic: An online student survey. Healthcare. Multidisciplinary Digital Publishing Institute.

Portoghese, I., Galletta, M., Porru, F., Burdorf, A., Sardo, S., D'Aloja, E., et al. (2019). Stress among university students: Factorial structure and measurement invariance of the Italian version of the effort-reward imbalance student questionnaire. BMC psychology., 7(1), 1-7.

Prazeres, F., Passos, L., Simões, J. A., Simões, P., Martins, C., \& Teixeira, A. (2021). COVID-19-related fear and anxiety: Spiritualreligious coping in healthcare workers in Portugal. International Journal of Environmental Research and Public Health., 18(1), 220.

Reicher, S., \& Drury, J. (2021). Pandemic fatigue? How adherence to covid-19 regulations has been misrepresented and why it matters. bmj, 372:n137

Savitsky, B., Findling, Y., Ereli, A., \& Hendel, T. (2020). Anxiety and coping strategies among nursing students during the covid-19 pandemic. Nurse Education in Practice, 46, 102809.

Savitsky, B., Findling, Y., Ereli, A., \& Hendel, T. (2021). Nursing students in crisis mode: Fluctuations in anxiety during the COVID19-related lockdown. Nurse Educator., 46(3), E33.

Sharma, K., Saji, J., Kumar, R., \& Raju, A. (2020). Psychological and anxiety/depression level assessment among quarantine people during Covid19 outbreak. Journal of Drug Delivery and Therapeutics., 10(3), 198-201.

Smith, B. W., Dalen, J., Wiggins, K., Tooley, E., Christopher, P., \& Bernard, J. (2008). The brief resilience scale: Assessing the ability to bounce back. International journal of behavioral medicine., 15(3), 194-200.

Tolin DF, Foa EB. Sex differences in trauma and posttraumatic stress disorder: A quantitative review of 25 years of research. 2008

Vishwakarma, D., Ravi, R. P., \& Thomas, E. (2021). Impact of COVID-19 pandemic on mental health and effects of a sense of verdict of selected college students in Nepal, Nigeria and India. EXECUTIVE EDITOR, 12(1), 60. 
Volkan, E., \& Volkan, E. (2020). Under the COVID-19 lockdown: Rapid review about the unique case of North Cyprus. Psychological Trauma: Theory, Research, Practice, and Policy, 12(5), 539.

Wasil, A. R., Franzen, R. E., Gillespie, S., Steinberg, J. S., Malhotra, T., \& DeRubeis, R. J. (2021). Commonly reported problems and coping strategies during the COVID-19 crisis: A survey of graduate and professional students. Frontiers in Psychology, 12, 404.

Xiao, Y., \& Torok, M. E. (2020). Taking the right measures to control COVID-19. The Lancet Infectious Diseases., 20(5), 523-524.

Zhang, L., Wang, L., Liu, Y., Zhang, J., Zhang, X., \& Zhao, J. (2021). Resilience predicts the trajectories of college Students' daily emotions during COVID-19: A latent growth mixture model. Frontiers in Psychology, 12, 644.

Publisher's note Springer Nature remains neutral with regard to jurisdictional claims in published maps and institutional affiliations. 